\title{
Changing Education to Meet the Needs of Future Informing Science Clients: Suggestions for New Curriculum Frameworks
}

\author{
Sanjeev Phukan \\ Bemidji State University, USA
}

sphukan@bemidjistate.edu

\begin{abstract}
In the last 10 years we have seen enormous and dramatic changes in the way we view and use Information. These changes have had far reaching effects, including, but certainly not limited to, the creation of a complex and vibrant global economy, and a sea change in the way we live, work and play. Profitability and survival are increasingly contingent upon an ability to successfully operate in this global arena. Technology has played a pivotal role in the creation of this global economy and will be a crucial determinant of success for organizations that operate within it. These organizations must and will demand a comprehensive array of attributes and skills from their personnel. Information Systems (IS) professionals particularly will be called upon to provide their clients with relevant and timely information, which is a major component of the concept of an "Informing Science” as presented.
\end{abstract}

Keywords: Global Economy, Information Technology, Informing Science, Survival, Profitability, Education.

\section{Information in a Global Economy}

The last decade has seen major changes in the way we view and utilize Information Technology (IT), including computers, communications, and office automation. The effects of these changes have been widespread and as a result, have caused major transformations in the way we live and work. One major shift has been in the way we now view the use and management of information. As information and its use becomes a major determinant of success and profitability, professionals are increasingly focused on the delivery and management of information as a key resource. The concept of an "Informing Science" (IS) which seeks primarily to provide a client with information in a form, format, and schedule that maximizes its effectiveness (Cohen, 1999) has enormous relevance in today's information intensive society.

A significant reason behind the way we now view information and its use has been the creation of a global

Material published as part of this proceedings, either on-line or in print, is copyrighted by the author with permission granted to the publisher of Informing Science for this printing. Permission to make digital or paper copy of part or all of these works for personal or classroom use is granted without fee provided that the copies are not made or distributed for profit or commercial advantage AND that copies 1) bear this notice in full and 2) give the full citation on the first page. It is permissible to abstract these works so long as credit is given. To copy in all other cases or to republish or to post on a server or to redistribute to lists requires specific permission from the author. marketplace on a scale that could hardly have been imagined as little as two decades ago. This has created an unprecedented variety of new clients for information. In addition, this marketplace has shrunk the world in such a way as to create tremendous opportunities as well as threats for even relatively small organizations. As a consequence, many organizations today have discovered that their profitability and perhaps even their survival, now depend on their ability to successfully play the game in a new, complex, and often unfamiliar, global arena.

More and more organizations today view the entire world as their market, and a significant proportion have come to the realization that their greatest opportunities for profits and growth may in fact lie outside the boundaries of their "home" country. These organizations are affected by events and activities that occur all over the world, not just in the region where their "home" office happens to be located. Thus, while we may previously have viewed a corporation's international operations as an extension of its domestic activity, this viewpoint may no longer be appropriate in many instances. In fact, although political boundaries between countries technically still do exist, a map that shows the real flows of financial and industrial activity will demonstrate that these boundaries have largely disappeared (Ohmae, 1989). For example, although the European Union is yet to become a full-fledged reality, 


\section{Changing Education to Meet the Needs of Future Informing Science Clients}

the concepts behind it distinctly demonstrate the direction in which nations and regions appear to be moving. It is apparent that far stronger relationships between nations and regions are created on the platform of trade than on the basis of any alignment of political ideology.

Today the number of companies that have some form of international, if not global presence is dramatically higher that what it was just a few years ago. Even small companies routinely have contacts with geographically distant lands, either as markets for their products or as sources for these same products. Terms of definition for these organizations have also increased; today we speak of multinational, transnational and virtual corporations. These corporations increasingly use IS and IT as strategic and operational tools to manage geographically dispersed enterprises. Goods and services are transported from locations scattered all over an increasingly shrinking globe to customers that may be equally scattered.

Much of current worldwide economic activity depends on the operations of organizations such as these (Egelhoff, 1991). Enormous advances in IT and IS have brought global markets and global competition to the doorstep of even the smallest companies (Cash et al, 1992, Neumann, 1992). The first aspect offers opportunities, the second, threats. It is safe to say that almost no major industry has escaped the effects of this globalization. A visit to an automobile dealership to examine the breakdown of source locations for the parts in a single automobile model demonstrates an almost incredible diversity of purchase points. A Boeing 747-400 may be assembled in Washington, but its components are made around the world. A department store emphasizes this even more dramatically. An examination of the products on a typical shelf reveals a veritable United Nations. Often we are surprised at the origin of a product that we had always assumed as being manufactured domestically. Thus, our homes have Christmas trees that are made in China, clothes from Sri Lanka, shoes from Indonesia and Italy, wood products (surprisingly) from Taiwan, computer keyboards from Singapore, grapes from Chile, and so on. In fact, a close examination of the products we use and live with every day might reveal that more of the products that we use are manufactured overseas rather than at home. Very little is really local anymore, and to many businesses, any place in the world is pretty much the same as any other place. In the words of Jim Hoagland, a columnist for the Washington Post, "anywhere is rapidly becoming everywhere."
Perhaps some of the most dramatic perspectives on this globalization are provided by firms that are in the technology business. By their very nature, technology firms have a firmly entrenched global presence, and the work that they do seems to ignore the boundaries of states, geography, and time. For instance, programmers in one US company working on new system development, work till 5:00 p.m. and then hand over to several thousand programmers in India. Callers for technical support in the wee hours of the morning in the United States might very well find themselves talking to someone in Ireland. The tremendous shortage of technology professionals has resulted in a worldwide "head-hunt", or as one recruiter uncharitably put it, "nerdhunt" for qualified professionals. Obviously, teams of professionals assembled from all over the world are going to present rather unique management challenges. And even though companies today are scrambling to hire almost anyone who even vaguely resembles an IS professional, maturity in the market will place increasingly complex demands on these personnel.

Companies and countries have reacted in many different ways to the challenges of. Strategic and operational trade and monetary alliances are one example. The EU and NAFTA are cases in point, and their success or failure, I believe, as yet remains unproven. Corporations have had to re-engineer the way they do business in order to operate in the global arena. It is obvious that the skills that an individual must possess to perform effectively in this arena are different from what they might have been twenty years ago. More than ever, the concept behind an Informing Science, one which seeks to provide a client with information in a form, format and schedule that maximizes its effectiveness (Cohen, 1999) must be understood by these individuals. Although educational institutions are scrambling to change their curricula to meet the expectations of the marketplace, I fear that this change is too slow and often in the wrong direction.

In the United States we have been fortunate to enjoy a period of unprecedented economic stability and growth. To be complacent, however, would be foolish. As most of us know, economic circumstances can rapidly change. Today, more than ever, our fortunes are inextricably tied to the economic well being of regions around the globe. The recent economic crisis in SouthEast Asia has provided ample evidence of this fact. We also need to be aware that many industries that were once mainstays of the US economy have either been entirely lost to foreign competition or have been overshadowed because of their inability to compete effectively in the global marketplace. Since 
globalization will be a continuing and even increasing trend (Neumann, 1992), corporations will need to be vigilant to the threats of global competition. They also need to be aware that the information technology that has driven this globalization has created an entirely different kind of economy - an information economy that is as different from a manufacturing economy as the manufacturing economy was different from the agricultural economy that prevailed at the turn of the century.

\section{Implications}

What does this really mean for business? The future will include both opportunities as well as potholes. Those companies that seize the opportunities by being adequately prepared, by optimizing efficiency, by responding quickly to changes in the global marketplace, by continually learning, will likely succeed (Bartlett and Ghosal, 1987, Porter and McKibbin, 1988, Porter and Millar, 1979). Many companies will try to succeed by pursuing a truly global business strategy. These firms would treat the world as a single, linked resource (Nelson, 1996). Companies that do not change will probably discover that they are ill equipped to meet the challenges of rapidly changing markets and foreign competition. Survival, or at least profitability, will be difficult to achieve.

The global marketplace is an increasingly complex and volatile marketplace. To effectively operate in this environment, businesses have little choice but to become information based. (Drucker, 1988). As previously mentioned, IS and IT have played key roles in the development of this global marketplace and will continue to be of strategic importance to firms that wish to operate successfully in this arena. The use of IS and IT for competitive advantage, to change and streamline organization structures, to bring efficiency to operations and to cope with increased levels of complexity and uncertainty is well established (Cash et al, 1992, Davis, 1986, McFarlan, 1992, Porter, 1990, Porter and McKibbin, 1988, Roche, 1992). Thus, IT and IS become the tools by which companies expect to prosper in the years ahead. The effectiveness of a company's IS will have much to do with its continuing success. The global marketplace demands the additional dimension of a global orientation for this IS (Benjamin et al, 1984, Ives and Jarvenpaa, 1991, Karimi and Konsynski, 1991). Global companies must deal with a diversity of products, markets, nations and cultures. Thus, they regularly must deal with issues that are far more diverse and complex than those encountered by even by even the largest domestic firms (Egelhoff, 1991). If one examines the issues and concerns that are involved in the management of a domestic IS operation, those in the corresponding global counterpart are usually far more extensive. The potential rewards offered by the creation of an effective global IS organization are usually more than enough to offset these difficulties, however. Technology can provide tremendous advantages in overcoming barriers such as time zone differences, geographic separation and training difficulties. In the small world created by today's technology almost all businesses will participate in the global marketplace in some way or another. Even smaller companies will find potential benefits in an effective global IS (Neumann, 1992), because technology allows even the smallest firms to become global. The lure of potential benefits offered by larger markets, growth, and profitability often play a prominent role in the long term strategic plans of most companies. Effective use of technology in the global marketplace can allow smaller entities, whether they be companies or countries, to successfully compete with their larger counterparts. Singapore's use of EDI with its TRADENET trade document processing system is an excellent example (King and Konsynski, 1992), allowing the port authority to move more cargo than any other port in the world. An island nation of about 600 square kilometers (230 square miles), Singapore's natural resources are conspicuous by their absence. Yet, in the last 30 years, she has taken her place in the world as a developed, newly industrialized, and technologically advanced nation. The government of Singapore has been firmly committed to technology, even going so far as to bring fiber-optic cable into every apartment house in the nation. This national commitment to technology is certainly one of the primary reasons for the country's advancement (Gable and Raman, 1992). As a result, Singapore's technology infrastructure is one of the most advanced in the region and compares favorably with much of the rest of the world. Small wonder then that Singapore enjoys an excellent standard of living and an impressive per capita GDP. The extensive technology investment, which has led to an excellent communication and computing infrastructure and the availability of skilled IS professionals has also been a catalyst for massive increases in foreign direct investment in Singapore.

As is obvious from the discussion above, technology has played a crucial and pivotal role in the creation of this global economy, and will have an enormous impact on its future. The management of organizations that must and will operate in this environment now and in the future will demand a comprehensive array of attributes and skills from their personnel. IS professionals particularly will be sub- 


\section{Changing Education to Meet the Needs of Future Informing Science Clients}

ject to an increasing list of demands. As is already often the case, in many instances IS personnel, much more so than their counterparts in other functional areas, will be truly 'global' personnel, living and working in places that are often far removed from where they were born or educated. It is here that the perspective provided by Informing Science has the potential to change the way we educate and train future global IS personnel.

\section{IT Personnel in the Future: A Focus on Informing Clients}

In many ways today's global economy is reminiscent of the age of empires. During that period, professionals had to have a working knowledge of other areas of the world, notably the various colonies of the mother country. Toward this end there was the grand tour, an education strongly based in the liberal education traditions of history, geography, languages, and the arts, and the somewhat dubious distinction of always having the upper hand as a citizen of the ruling country. Circumstances today are vastly different; nevertheless certain lessons are still valid. The imperial powers, from Rome to Britain, ensured that their professionals had a thorough understanding of the cultures and values of the areas to which they were sent. Those who did not possess this understanding proved to be incapable of operating effectively. Today's global professionals also have to deal with a wide range of problems. IS personnel may face a host of issues that may range from technical telecommunications issues to global corporate management (Deans et al, 1991). In addition, they must be familiar with other, non-technical issues as well, such as culture and tradition. The management of a global IS thus poses special challenges for IS managers (Deans and Ricks, 1993) and the global IS professional will need a far greater depth and breadth of knowledge in comparison to his or her domestic counterpart (Cheney and Kasper, 1993). Global Information Systems professionals will also need to have international experience in interactions with global competitors and global customers (Nelson, 1996). It goes without saying that the successful global IS professional will need be familiar with IS standards and practices in other areas of the world.

Many authors have attempted to define the characteristics that a successful global IS professional must possess. For example, in his examination of the role of a global Chief Information Officer (CIO), Roche (1992) suggests that the CIO's task must include the construction of short-term infrastructure requirements with the flexibility to meet the longer-term needs of the global organization. This is a tall order.

Surely one of the most daunting aspects of the task faced by any global IS professional is what can only be described as the simultaneous management of several learning curves. He or she must be well versed in the IS organization, the different national organizations, the corporation as a whole, and the country management. This is above and beyond any technical skills, which must be taken for granted.

Factors such as the geographic transfer of work, global networking, global service levels, time based competition and cost cutting have all contributed to the increasing importance of global IS, and consequently to the increased reliance on global IS personnel. More than ever, clients rely on these IS personnel to receive the information that they need in a form and format that is relevant. In order to meet these demands, these global IS professionals must deal with a variety of additional transnational problems, including those of inadequate infrastructure, sketchy technical support, language problems, geographic separation, differing time zones, and greatly different labor technology cost tradeoffs.

Perhaps it is not possible to arrive at a comprehensive list of the skills and attributes that a global IS professional must possess. And maybe this is not entirely a disadvantage. A contingency approach could then be used, where a global IS professional is gradually eased into the global arena during his or her career. This would still necessitate, however, a certain broad based background that would have to be provided by the educational process.

\section{New Curriculum Frameworks}

To meet the requirements outlined above, IS education across the world would have to provide a 'base foundation' of skills and knowledge. This foundation must be easily transportable across nation and regions and must emphasize the delivery of information to a client in a form, format, and schedule that maximizes its effectiveness. I believe that technology graduates the world over will require these and other specific skills to succeed in a fast moving marketplace that will be characterized by a culturally and ethnically diverse work force and a significant dependence on technology to cut across many barriers. In order for technology graduates to change their focus to one where they are the "server" in a client-server" situation, and for them to be able to address the needs of developed, 
developing, and under-developed markets, they will require an expanded technology curriculum substantially different from the vast majority that are in place today. All over the world, universities and institutions of higher learning will need to confront the problem of creating curricula that will meet these requirements of a dynamic and rapidly changing world market.

The problem has several dimensions. As the worldwide demand for technology professionals grows, educational institutions have been scrambling to try and produce enough graduates to satisfy the burgeoning market. However, concurrent rapid changes in the technology environment and explosive growth and change rates in technology have made the development of a viable IT curriculum extremely difficult. Add to this a focus on "informing clients in a global setting", and most curriculum initiatives seem to be only too relieved to shove it onto a remote back burner.

The real problem, I believe, lies in determining exactly what the content of these curricula should be. It appears, at least at first glance, that curricula in many regions of the world, while attempting to provide an increasing number of IT skill sets, have done little to address the real problems inherent in creating a technology professional who serves his or her clients in a global marketplace. Demands on institutions of higher learning will become increasingly stringent in the next century, and curriculum issues will become the focus point for many IT educators. There is little help from existing curriculum models. Many models seem to be unsure of what and undergraduate degree in IS should provide and most certainly do not address the issue of informing clients in a global setting.

Even though the definition of Informing Science as outlined by Cohen (1999) is a broad one that goes beyond Information Systems or technology professionals, I believe that the Informing Science personnel of the future will evolve from the Information Systems and Technology personnel of today. Providing information in a complex and rapidly changing world will be easiest, I believe, through the effective use of technology, and will therefore require the involvement of IT personnel. I believe therefore, that the best way to address the requirements of informing clients in a global setting is to create a new, changed, breed of IS (Information Systems or Informing Science!) personnel. The creation of this new breed of professionals will be a challenge, the resolution of which will require cooperation between IS practitioners, corporate executives, and academics (Neumann, 1992). I think an appropriate start- ing point is an examination of IS education and an overhaul of the curriculum.

\section{Conclusion}

I would like to conclude with the following: 1 . An everincreasing number of organizations will rely on an interconnected global economy for their continued good health. 2. Success in this global economy will to a large extent be determined by how effectively they use information. 3 . Managing information and its associated technology on a global scale is likely to be a complex process that will need IS personnel with special skills and attributes. 4. Educators and businesses are going to have to cooperate on the creation of these individuals; neither can achieve the desired results on their own. 5. Assuming that education is the preliminary step in this process, curriculum changes will be necessary and resources must be made available to bring about these changes. IS curricula today are for the most part devoid of an international element and do not focus on servicing the information client. When attempts are made to change these curricula, the focus may very well need to be on classes that fall outside the bounds of what is normally considered to constitute an IS education.

\section{References}

Bartlett, C. A., \& Ghosal, S. (1987). Managing Across Borders: New Organizational Responses. Sloan Management Review, 29(1), 4353.

Benjamin, R. I., Rockart, J. F., Scott-Morton, M. S., \& Wyaman, J. (1984). Information Technology: A Strategic Opportunity. Sloan Management Review, Spring 1984, 1-10.

Cash, J.I., McFarlan F. W., McKenney, J. L., \& Applegate, L. M. (1992). Corporate Information Systems Management, 3/e. Homewood: Irwin.

Cheney, P. H., \& Kasper, G. M. (1993). Responding to World Competition: Developing the Global IS Professional. Journal of Global Information Management, 1(1), 21-31.

Cohen, E. (1999). Reconceptualizing Information Systems as a Field of the Transdiscipline Informing Science: From Ugly Duckling to Swan. Journal of Computing and Information Technology. 7 (3), 213-219.

Davis, G.R. (1986). MBA Students Need More MIS. Datamation, September 1, 1986, p.19.

Davis, G. B., Gorgone, J. T., Couger, J. D., Feinstein, D. L., \& Longenecker, H. E. (1997). IS '97: Model Curriculum and Guidelines for Undergraduate Degree Programs in Information Systems. Chicago: AITP. 


\section{Changing Education to Meet the Needs of Future Informing Science Clients}

Deans, P. C., \& Goslar, M. D. (1993). Alternative Curriculum Approaches for Global IT Education Settings. In M. Khosrowpour and K. D. Loch (eds.) Global Information Technology Education. Harrisburg: Idea Group.

Deans, P. C., Karwan, K. R., Goslar, M. D., Ricks, D. A., \& Toyne, B. (1991). Identification of Key International Information Systems Issues in U.S.-Based Multinational Corporations. Journal of Management Information Systems, 7(4), 27-50.

Deans, P. C., \& Ricks, D. A. (1993). An Agenda for Research Linking Information Systems and International Business: Theory, Methodology and Application. Journal of Global Information Management, 1(1), 6-19.

Drucker, P. F. (1988). The Coming of the New Organization. Harvard Business Review, 66(1), 45-53.

Egelhoff, W. G. (1991). Information Processing Theory and the Multinational Enterprise. Journal of International Business Studies, 22(3), 341-368

Gable, G. G., \& Raman, K. S. (1992). Government Initiatives for IT Adoption in Small Business: Experiences of the Singapore Small Enterprise Computerization Program. International Information Systems, 1(1), 68-93.

Ives, B., \& Jarvenpaa, S. L. (1991). Applications of Global Information Technology: Key Issues for Management. MIS Quarterly, 15(1), 33-49.

Karimi, J., \& Konsynski, B. R. (1991). Globalization and Information Management. Journal of Management Information Systems, 7(4), $7-26$.

King, J., \& Konsynski, B. R. (1992). Singapore Tradenet: A Tale of One City. In J. I. Cash, F. W. McFarlan, J. L. McKenney and L. M. Applegate. Corporate Information Systems Management. Homewood: Irwin.
McFarlan, F. W. (1992). Multinational CIO Challenge for the 1990s. In S. Palvia, P. Palvia and R. M. Zigli (eds.). The Global Issues of Information Technology Management. Harrisburg: Idea Group.

Nelson, K. (1996). Global Information Systems Quality: Key Issues and Challenges. Journal of Global Information Management, 4(4), 414.

Neumann, S. (1992). Issues and Opportunities in International Information Systems. International Information Systems, 1(4), 1- 13.

Ohmae, K. (1989). Managing in a Borderless World. Harvard Business Review, May-June 1989.

Porter, L. W., \& McKibbin, L. E. (1988). Management Education and Development: Drift or Thrust into the 21st Century? New York: McGraw-Hill.

Porter, M. E., \& Millar, V. E. (1979). How Information Gives You Competitive Advantage. Harvard Business Review, March-April 1979, 137-145.

Porter, M. E. (1990). The Competitive Advantage of Nations. Harvard Business Review, 90(2), 73-93.

Roche, E. M. (1992). Managing Information Technology in Multinational Corporations. New York: MacMillan.

Singapore Facts and Pictures (1993). Singapore Ministry of Information and the Arts, Singapore.

\section{Biography}

Sanjeev Phukan is a Professor of Information Systems at Bemidji State University, where he teaches in the areas of Operations Management and Information Systems. He has authored over 20 articles and papers on Information Systems Ethics and the global proliferation of technology. 